enough of its great men; but here an effort by a competent writer has been made, with sincerity, fairness, and critical acumen, to correct much of the ignorance.

It is still true, notwithstanding the revelations of science, that man's deepest problems lie within his own heart and it is also true that today one of the most efficacious solutions of them (in their economic aspect) is life insurance. When ${ }_{x}$ how, and why this has come to pass is shown for every reader in this fascinating volume.

\title{
Bank Records Acquired by the Society
}

The Business Historical Society has recently received from the First National Bank of Boston, through the courtesy of Mr. R. W. Stanley, eleven volumes of the original records of the Shoe and Leather Dealers' Bank, of Boston, which became the Shoe and Leather National Bank. These volumes include the minutes of stockholders' meetings for 1836 to 1865 and 1886 to 1893 , as well as directors' minutes from the beginning of the bank till 1901. The collection also includes two account books of the Blackstone National Bank of Boston, whose liquidation was in the hands of the Shoe and Leather National Bank.

The Shoe and Leather Dealers' Bank was established in 1836 by men in the then rapidly expanding shoe and leather industry of Boston. How far this bank continued to serve the shoe industry a careful study of the records may reveal. In 1901 its separate existence ended with its merger with the National Bank of Redemption, which in 1904 was absorbed by the First National Bank of Boston. 